\title{
Qualidade das Escolas: tensões e potencialidades das avaliações externas
}

\author{
Cristiane Machado' \\ Ocimar Munhoz Alavarse"
}

'Universidade do Vale do Sapucaí (Univás), Pouso Alegre/MG - Brasil "Universidade de São Paulo (USP), São Paulo/SP - Brasil

RESUMO - Qualidade das Escolas: tensões e potencialidades das avaliações externas. A partir do debate sobre qualidade na educação, este trabalho objetiva evidenciar o fortalecimento das iniciativas de avaliações externas como diretriz da política educacional para a melhoria da qualidade da educação das escolas. Apoiando-se na pesquisa nacional, procura-se mostrar possíveis interfaces das avaliações com a qualidade da educação. São destacadas algumas potencialidades e, também, alguns indícios de tensões das políticas de avaliação no cotidiano escolar. Por fim, conclui-se que a avaliação externa, concebida como um processo amplo que envolve escolhas técnicas, políticas e ideológicas, é um importante instrumento para o incremento da qualidade da educação nas escolas públicas.

Palavras-chave: Qualidade do Ensino. Avaliação Externa. Escolas Públicas. Ensino Fundamental.

ABSTRACT - School Quality: impacts and challenges of external evaluation. From the debate on quality in education this work aims at identifying the strengthening of initiatives external evaluations of educational policy as a guideline for improving the quality of education in schools. Drawing on national survey try to show possible interfaces of evaluations with the quality of education. Are highlighted some potential, and also some evidence of political tensions evaluation in school life. Finally, it is concluded that the external evaluation, conceived as a broad process that involves technical choices, political and ideological is an important tool to increase the quality of education in public schools.

Keywords: Quality of Teaching. External Evaluation. Public Schools. Elementary School.

Educação \& Realidade, Porto Alegre, v. 39, n. 2, p. 413-436, abr./jun. 2014. 
Qualidade das Escolas

Embora o debate em torno do tema da qualidade não seja novo no contexto educacional brasileiro, sua relevância ganhou maior destaque nas últimas décadas, principalmente com a ampliação do acesso de amplos contingentes que antes estavam alijados da escola e, também, pela expansão de políticas de avaliação de sistemas que evidenciou a profunda dificuldade de oferecimento de uma educação pública que conseguisse garantir o domínio de conhecimentos básicos a todos os alunos, como expuseram Alves (2009) e Oliveira (2007), associando, ainda que com matizes, qualidade com desempenho em provas padronizadas.

Vale ressaltar que esses elementos são encontrados em escala mundial, como destacam Adams, Acedo e Popa (2012). Esses autores destacam evidências de que, após a Conferência de Jomtien, em 1990, dois traços são recorrentes nas políticas educacionais da imensa maioria dos países. Um deles refere-se à consideração de que a educação escolar é condição indispensável para o desenvolvimento econômico, notadamente para os países caracterizados como emergentes. O outro traço é a preocupação com a qualidade, que majoritariamente vai sendo associada a desempenho em provas padronizadas, neste caso com uma pressão de muitas agências e bancos de fomento, ainda que isso, paradoxalmente, não tenha estabelecido uma definição peremptória de qualidade da educação escolar. Tal quadro tem desdobramentos que podem ser detectados nas preocupações com a gestão de escolas, como sublinha Bolívar (2012), mais recentemente, ou em OCDE (1992), ainda nos primórdios dessa guinada.

No Brasil, iniciativas de avaliação de sistemas foram amplificadas e fortalecidas a partir de 1990, com a criação, pelo governo federal, do Sistema de Avaliação da Educação Básica (SAEB). Na sua fase inicial, o SAEB tinha como objetivo principal fornecer informações sobre o desempenho dos sistemas educativos para gestores educacionais, famílias e sociedade e, para tanto, aplicava questionários e provas amostrais a cada dois anos.

Fatores como critérios de inclusão/exclusão de alunos, adequação de matriz curricular, precisão dos instrumentos avaliativos, dentre outros, impulsionaram diversas revisões na metodologia e escopo do SAEB, fazendo com que o sistema passasse por várias fases. Em 2005, o governo desdobrou o SAEB em mais uma prova, a Prova Brasil, de caráter censitário, viabilizando a criação de um instrumento de gestão dos sistemas e das unidades escolares (Sousa; Lopes, 2010), a partir da disponibilização pública dos resultados da avaliação de cada uma das redes de ensino e escolas do país.

Apoiando-se nos dados gerados pela Prova Brasil, foi criado, em 2007, o Îndice de Desenvolvimento da Educação Básica (IDEB), com o objetivo de ser um indicador de qualidade da educação (Fernandes, 2007). Para o ensino fundamental de redes públicas o Ministério da Educação (MEC) divulga, a cada dois anos, o IDEB do Brasil, dos esta- 
dos, municípios e das escolas obtido a partir das taxas de aprovação e das proficiências dos alunos na Prova Brasil, dentro de uma escala de 0 a 10. Adicionalmente, foram fixadas em 2007 metas a serem alcançadas para cada um desses segmentos.

A criação da Prova Brasil e do IDEB colocaram o debate sobre a qualidade da educação brasileira em outro patamar. Por um lado, a Prova Brasil, ao utilizar a metodologia censitária de avaliação, impeliu, não sem controvérsias e resistências, a comunidade escolar a se reconhecer nos seus resultados, ao mesmo tempo, o IDEB, ao tornar público o desempenho das redes de ensino e de cada uma das escolas, aproximou os mais diversos segmentos da sociedade de um valor de referência da qualidade da rede do seu município e da escola de seu bairro.

Esse novo contexto coloca ainda mais a escola pública em evidência, expondo os resultados do seu trabalho e ampliando a pressão pelo aumento das suas notas, entendido geralmente como melhoria da qualidade do ensino praticado. Assim, este trabalho tem a finalidade de analisar a qualidade das escolas por meio da reflexão dos resultados da avaliação externa, buscando ressaltar as tensões e as potencialidades dessa política para o cotidiano das unidades educacionais e para o alargamento da qualidade do ensino praticado.

\section{Qualidade, Avaliação Externa e IDEB: conceituação}

Conceituar qualidade na educação é tarefa hercúlea, embora tenha sido convertida em "meta compartilhada", “[...] palavra de ordem mobilizadora, em um grito de guerra em torno do qual se devem juntar todos os esforços" (Enguita, 1994, p. 95). Gentili (1994) traz o tema para uma reflexão mais profunda ao afirmar que seu surgimento no campo educacional se desenvolveu na América Latina, a partir do final da década de 1980, para se contrapor ao discurso da democratização. Ainda assim, cabe-nos concordar com a assertiva de Casassus (2007, p. 41) “[...] a qualidade da educação, como objetivo, tornou-se um conceito estratégico nas formulações de política educacional na grande maioria dos países”.

O tema, ainda, é robusto em ambiguidade (Risopatron, 1991, p. 15), polissemia (Dourado, 2007, p. 07) e historicidade (Silva, 1996). Sousa (1997a, p. 267) destaca que “[...] qualidade não é 'algo dado', não existe 'em si', remetendo à questão axiológica, ou seja, dos valores de quem produz a análise de qualidade". Azevedo (1994, p. 456) afirma que “[...] qualidade não é um atributo neutro, nem é desprovida das significações que lhe reservam os agentes que dela estão tratando, de acordo com seus interesses e valores específicos".

Gusmão (2013, p. 123), em estudo baseado em entrevistas com diversos atores sociais do campo educacional sobre noções de qualidade, apontou a existência de convergência, apesar das diferenças de

Educação \& Realidade, Porto Alegre, v. 39, n. 2, p. 413-436, abr./jun. 2014.

Disponível em: <http://www.ufrgs.br/edu_realidade> 
interesses políticos constatada entre esses agentes, dos discursos para duas dimensões:

1) a elevação do desempenho dos estudantes nas provas de larga escala; e 2) a garantia de condições variadas de ensino que conduzam a uma formação ampla dos estudantes, abrangendo não só os conteúdos curriculares, como também a cidadania e capacidades éticas.

A autora (Gusmão, 2013, p. 123) salienta, ainda, como conclusão que:

Todos convergem ao defender uma educação que de fato proporcione boa formação a estudantes, orientada para o desenvolvimento significativo de cada pessoa e da sociedade como um todo e combatendo uma escolarização que passe 'em branco' na vida das crianças e adolescentes. Para uns, isso se traduz em garantir aprendizagem capaz de ser medida pelas provas padronizadas; para outros, em priorizar processos, condições e uma aprendizagem mais ampla, que envolve os 'conteúdos' disciplinares e a cidadania.

Portanto, qualidade não é um conceito simples e muito menos imparcial. Nesse emaranhado de 'qualidades' do conceito qualidade, cabe-nos, antes de prosseguir, definirmos o que entendemos por qualidade. Nesse sentido, concordamos com Dourado (2007, p. 09), que qualidade da educação é "[...] um fenômeno complexo, abrangente e que envolve múltiplas dimensões".

Aproximando o debate da qualidade do foco desse estudo, a escola, Soares (2012, p. 83) é mais preciso na sua definição de qualidade, diz o autor que

[...] a escola de qualidade é aquela quem tem como valor fundamental a garantia dos direitos de aprendizagem de seus alunos, dispõe de infraestrutura necessária, ensina o que é relevante e pertinente através de processos eficazes e utiliza os recursos disponíveis, sem desperdícios. Seus professores e funcionários e os pais dos alunos estão satisfeitos e os alunos mostram, através de formas objetivas que aprenderam o que deles se esperava.

Assim, sabemos que os conteúdos das avaliações externas, desempenho em leitura e resolução de problemas, não resumem $a$ qualidade da escola, porém, esses itens não são alheios ao processo escolar que se pretenda de qualidade.

Mesmo com toda a ambiguidade que envolve a conceituação de qualidade, em relação à qualidade das escolas é possível reconhecer nas políticas educacionais e na literatura importantes inflexões que procuram associar indícios de qualidade à avaliação externa, embora estejamos longe de um consenso sobre a questão. 
O dimensionamento da qualidade da educação escolar se constitui num complexo problema político e pedagógico, pois concentram leituras da sociedade, da escola e das relações que entre elas se estabelecem. Oliveira e Araújo (2005) demarcam o debate apontando a necessidade de que os resultados de avaliações externas sejam incorporados sem que, contudo, se estabeleça determinismo nas relações entre eles e o trabalho dos professores, como se estes fossem os únicos e plenamente capazes de engendrar os resultados escolares. Fernandes e Gremaud (2009) sinalizam com a necessidade de medidas de accountability - expressão inglesa traduzida mais comumente como responsabilização - para que houvesse incidência dos resultados dessas avaliações nas escolas. Para Castro (2007, p. 61), a qualidade da educação se expressa nos resultados de provas padronizadas e que, mesmo reconhecendo as precariedades na atividade docente, incluindo a sua remuneração, sustenta que a melhoria dos salários dos professores se daria pela "[...] implantação de salários diferenciados mediante desempenho. Para isto, o ideal seria estabelecer sistemas de avaliação dos professores vinculados aos resultados das escolas”. Em tal perspectiva, as avaliações externas, além da associação mecânica entre desempenho em provas e trabalho docente, desprezando frequentemente as condições das quais emergem esses resultados, confundem-se com um modelo de gerenciamento de recursos humanos, retirando-lhes todo o potencial pedagógico.

Por avaliação externa compreendemos a realização de provas padronizadas em larga escala, contemplando amplo contingente de participantes e resultando em um conjunto de informações que pode orientar ações das mais variadas ordens nas políticas educacionais para todos os níveis da federação.

Barreto e Pinto (2001, p. 57) analisam o estado da arte em avaliação educacional nos anos 1990 e salientam que os objetivos das avaliações em larga escala são descritos nos artigos estudados como “[...] os de delinear o perfil cognitivo da população com base em informações de caráter censitário, permitindo reconstituir detalhes da trajetória escolar de populações que frequentam a escola e identificar a transição de um estágio cognitivo dos sujeitos para outro". Destacam as autoras que os artigos também evidenciam uma preocupação com os novos modelos de organização da produção e a competência da mão de obra que está sendo formada para empregar tecnologia moderna, tendo a avaliação um papel de destaque para aferir essa competência.

O final dos anos de 1980 representou um marco significativo na implementação de um sistema nacional de avaliação da educação básica pelo Ministério da Educação, por meio da organização, elaboração e execução pelo INEP, com a criação efetiva do Sistema de Avaliação do Ensino Público de $1^{\circ}$ Grau (SAEP), em 1987, que teve o objetivo de avaliar o Programa de Educação Básica para o Nordeste Brasileiro, conhecido como Edurural (Bonamino, 2002). 
Qualidade das Escolas

O Sistema de Avaliação da Educação Básica (SAEB), cuja primeira edição ocorreu em 1990, tinha, segundo os dirigentes do MEC, dentre outros, os objetivos de: regionalizar a operacionalização do processo avaliativo para possibilitar a gestão direta pelas instâncias locais; conhecer e construir parâmetros do rendimento dos alunos em relação às propostas curriculares; disseminar na sociedade ideias em relação à qualidade desejada e a obtida, considerando o conhecimento a ser democratizado, perfil e prática dos professores e diretores e construir uma base de dados sobre o processo de ensino-aprendizagem nas escolas públicas (Pilati, 1994).

Cinco anos após sua implantação, em 1995, o SAEB passou por uma reformulação contemplando duas grandes alterações importantes. A primeira, em relação aos seus objetivos, que passou a incluir estudos e análises dos alunos do ensino médio e da rede particular, visava incorporar levantamentos de dados sobre as características socioeconômicas, culturais e sobre os hábitos de estudo dos alunos e redefiniu as séries avaliadas por amostragem, $4^{\mathrm{a}}$ e $8^{\mathrm{a}}$ séries do ensino fundamental e $3^{\text {a }}$ série do ensino médio (Coelho, 2008). A segunda, em relação à metodologia das provas, com a introdução da metodologia da Teoria de Resposta ao Item (TRI) para medir o desempenho dos alunos na perspectiva da trajetória histórica das aferições dos resultados obtidos nas provas, o que possibilitou, segundo Sousa e Arcas (2010, p. 182), “[...] comparações entre as diversas aplicações, criando-se, assim, uma série histórica, permitindo a elaboração de políticas públicas a longo prazo”. Nessa fase a avaliação externa teve o objetivo de produzir informações do desempenho dos alunos para a constituição de trajetórias históricas dos resultados obtidos pelas escolas, possibilitando a produção de políticas pedagógicas que pudessem significar avanço na aprendizagem dos alunos que demonstravam maiores dificuldades e, consequentemente, melhorar a qualidade da educação.

Na metade da década de 2000, precisamente em 2005, há outra importante reformulação do SAEB, que passou a ser composto - desdobrado - por duas avaliações. Uma delas foi a Avaliação Nacional da Educação Básica (ANEB), que manteve várias características originais do SAEB. A outra foi a Avaliação Nacional do Rendimento Escolar (ANRESC), conhecida com o nome de Prova Brasil.

O sítio do MEC relaciona as semelhanças e diferenças entre o SAEB e a Prova Brasil e esclarece que são dois exames complementares que compõem o Sistema de Avaliação da Educação Básica. Sobre as semelhanças o texto exposto destaca, dentre outras: as duas avaliações são aplicadas a cada dois anos e os alunos fazem provas que avaliam as habilidades em Língua Portuguesa (foco em leitura) e Matemática (foco na resolução de problemas). Em relação às diferenças o MEC ressalta, dentre outras, que: a Prova Brasil avalia apenas alunos do ensino fundamental de $5^{\circ}$ e $9^{\circ}$ anos, das escolas públicas urbanas e é universal; enquanto o SAEB, além dessas características, avalia também alunos 
do $3^{\circ}$ ano do ensino médio, da rede privada, das escolas nas áreas rural e é amostral. Ao final do texto o MEC informa que, embora o Sistema tenha sido desdobrado em duas avaliações, tendo em vista a metodologia utilizada, nenhum aluno precisará fazer duas provas.

Porém, uma diferença entre as duas avaliações tem importância crucial para a gestão das escolas. Enquanto a avaliação do SAEB sempre foi amostral, ou seja, apenas uma amostragem de alunos era avaliada, a Prova Brasil é censitária, ou seja, todos os alunos de todas as escolas são avaliados. Sob esse prisma, a possibilidade de não reconhecimento de alguma escola nos resultados da avaliação é inexistente, uma vez que seus alunos de ensino fundamental e/ou médio obrigatoriamente fazem parte do público avaliado, o que nem sempre acontecia com a avaliação amostral do SAEB.

Nesse sentido, Sousa e Lopes (2010, p. 55) ponderam que a diferença entre as avaliações externas, uma ser amostral e a outra censitária, é uma considerável justificativa para a criação de outro sistema de avaliação com as características da ANRESC, porém não é a única, pois, além disso, soma-se "[...] à necessidade de fazer da avaliação um instrumento de gestão para/das unidades escolares levou à proposição da Prova Brasil, cujos resultados estão disponíveis para cada uma das redes e para cada escola”. Porém, Correia (2010, p. 1) alerta para as profundas transformações ocorridas nos últimos 30 anos na gestão dos sistemas educativos em geral e chama a atenção para a "erosão" dos princípios fundantes do "Estado Educador" acompanhada da justificativa de "autonomia das escolas" que, usualmente, tem servido para responsabilizar as escolas e os professores pelos resultados escolares, quase sempre negativos. Para o autor (Correia, 2010, p. 2), essa relação entre autonomia e avaliação tem se fortalecido nos últimos 10 anos de tal forma que, considerando a existência de uma "avaliocracia”,

La centralidad que ha adquirido la evaluación en la gestión de los sistemas educativos ha sido acompañada por el desarrollo, estructuración y consolidación de un conjunto de relatos y protagonistas en el campo de la educación que configuran lo que podríamos llamar 'evaluocracia'. A través de múltiples y diversificados modos, esta 'evaluocracia' es particularmente propensa al desarrollo de un trabajo simbólico en el establecimiento de nuevas figuras y dispositivos institucionales dirigidos a una reconstrucción del campo.

Dentro desse debate, análise de Alavarse, Bravo e Machado (2012, p. 10) afirmam que:

Nesses novos tempos de avaliação, possíveis alegações de não reconhecimento das especificidades de cada rede nos resultados das avaliações por amostragem, como o SAEB, não encontram mais eco na sociedade, uma vez que a Prova Brasil e o IDEB produzem e disponibilizam uma foto- 
grafia da qualidade do ensino de cada sistema de ensino da federação.

No estudo de Bonamino e Sousa (2012, p. 379) encontramos alguns dados que evidenciam a relevância numérica da diferença entre as duas avaliações, como exemplo da extensão da ramificação do SAEB e da Prova Brasil, tendo em vista o contingente de alunos avaliados. As autoras destacam que,

\begin{abstract}
A introdução da Prova Brasil em 2005 e sua repetição, a cada dois anos, permitem a comparação, ao longo do tempo, entre as escolas que oferecem o ensino fundamental. Em sua primeira edição, ela avaliou mais de 3 milhões de alunos em aproximadamente 45.000 escolas urbanas de 5.398 municípios; foi muito além, portanto, do SAEB, que avalia, em média, uma amostra de 300.000 alunos.
\end{abstract}

Dois anos após a criação da Prova Brasil, em 2007, o governo federal criou o Índice de Desenvolvimento da Educação Básica (IDEB). Embora tenha sido criado em 2007 o governo projetou metas para as escolas e redes considerando os dados já obtidos com a aplicação da Prova Brasil e com o Censo Escolar em 2005. Reynaldo Fernandes (2007, p. 06), presidente do INEP à época da criação do IDEB, explicitou que esse índice estava sendo criado para ser um "um indicador de qualidade educacional" e também para possibilitar um "[...] monitoramento permanente e medição do progresso dos programas em relação às metas e resultados fixados" na educação brasileira.

Em geral, os resultados da Prova Brasil e do IDEB são divulgados de forma a permitir a elaboração de um ranking das melhores e piores escolas e sistemas do país. A nosso ver, essa apropriação dos dados, desatrelada de outras análises, é equivocada, pois impele as escolas e as redes à competição e não ao estudo minucioso da realidade educacional e suas dificuldades. Ou, como diz Gentili (1994, p. 151-152), “[...] a obsessão pela medição (traduzida na obsessão pelo ranking) leva a supor que este simples ordenamento hierárquico melhora por si mesmo o rendimento qualitativo dos estabelecimentos educacionais".

Nesse sentido, defendemos que a avaliação deve ser utilizada com outro referencial, assim como explicita Vianna (2005, p. 16)

\begin{abstract}
A avaliação não é um valor em si e não deve ficar restrita a um simples rito da burocracia educacional; necessita integrar-se ao processo de transformação do ensino/ aprendizagem e contribuir, desse modo, ativamente, para o processo de transformação dos educandos.
\end{abstract}

O IDEB surge oficialmente com o Plano de Metas Compromisso Todos pela Educação, por meio do Decreto no 6.074, de 24 de abril de 2007 e foi enfatizado como um dos aspectos mais relevantes do Plano de Desenvolvimento da Educação (PDE) por Fernando Haddad (2008), 
então Ministro da Educação. Tal apreciação é reafirmada por Saviani (2007, p. 1242-1243), para quem,

O que confere caráter diferenciado ao IDEB é a tentativa de agir sobre o problema da qualidade do ensino ministrado nas escolas de educação básica, buscando resolvê-lo. E isso veio ao encontro dos clamores da sociedade diante do fraco desempenho das escolas à luz dos indicadores nacionais e internacionais do rendimento dos alunos.

Esses clamores adquiriram maior visibilidade com as manifestações daquela parcela social com mais presença na mídia, em virtude de suas ligações com a área empresarial. Tal parcela só mais recentemente vem assumindo a bandeira da educação, em contraste com os educadores que apresentam uma história de lutas bem mais longa.

Weber $(2008$, p. 312) traz contribuições para o debate na mesma perspectiva ao admitir que,

Além disso, a fixação de metas em relação ao Índice de Desenvolvimento da Educação Básica - IDEB -, mediante consulta a banco de dados e visitas de inspeção, conduzirá evidentemente ao acompanhamento contínuo do processo escolar, não sendo possível antever em detalhes o seu formato, embora fique patente a importância atribuída às condições escolares, tanto materiais como pedagógicas. Ora, condições materiais dependem, certamente, das condições socioeconômicas de onde estão localizadas as unidades escolares, ou seja, primordialmente elas dependem de fatores extraescolares. As condições pedagógicas, se bem também se relacionem com o contexto social, remetem, por sua vez, a complexo aparato de formação docente - inicial e continuada -, acompanhamento e crítica da prática pedagógica, mas, sobretudo, à valorização da atividade docente consubstanciada em remuneração condizente e condições de trabalho adequadas - número de alunos por turma, jornada de trabalho, material didático disponível, incentivo ao intercâmbio, entre outros aspectos.

Como indicador, o IDEB combina os resultados de desempenho nas provas do SAEB com taxas de aprovação de cada uma das unidades - escolas e redes - para as quais é calculado. Todo esse processo é de responsabilidade do Instituto Nacional de Estudos e Pesquisas Educacionais Anísio Teixeira (INEP). O Decreto no 6.094 de 2007 apresenta o sentido da qualidade da educação expressada pelo IDEB:

Art. 3 - A qualidade da educação básica será aferida, objetivamente, com base no IDEB, calculado e divulgado periodicamente pelo INEP, a partir dos dados sobre rendimento escolar, combinados com o desempenho dos alunos, constantes do censo escolar e do Sistema de Avaliação da Educação Básica - SAEB, composto pela Avalia- 
Qualidade das Escolas

ção Nacional da Educação Básica - ANEB e a Avaliação Nacional do Rendimento Escolar (Prova Brasil).

Embora a concepção de qualidade associada ao IDEB seja um tanto reducionista, por não contemplar aspectos relevantes do processo pedagógico, é possível considerar algumas potencialidades no IDEB por conta de duas características: por facilitar uma apreensão, mesmo que parcial, da realidade educacional brasileira, aí destacadas suas escolas, e, sobretudo, por articular dois elementos que há muito tempo parecem ser antagônicos: o aumento da aprovação e o aumento do desempenho.

Apreciando as características e metodologia da formulação do IDEB, Franco, Alves e Bonamino (2007, p. 991) defendem que seu princípio é o "[...] de que qualidade da educação pressupõe que o aluno aprenda e passe de ano". O incremento do IDEB, a médio e a longo prazos, se dará pelo incremento desses dois fatores articulados com melhorias nas taxas de aprovação. Enquanto indicador, a questão consiste em dimensionar o seu potencial para contribuir no equacionamento e no enfrentamento de tarefas de planejamento educacional, uma vez que existem projeções do IDEB até 2020 para cada escola e rede, levando em conta, de alguma forma, as particularidades dessas unidades.

Nessa perspectiva, é necessário compreender a avaliação vinculando-a ao desafio da aprendizagem, o que deriva do esforço de desvinculá-la dos mecanismos de aprovação ou reprovação e, mais importante, destaca outra finalidade da avaliação educacional, no que se concentra sua verdadeira dimensão política, pois numa escola que se pretenda democrática e inclusiva as práticas avaliativas deveriam se pautar por garantir que, no limite, todos aprendessem tudo. Principalmente, quando nos reportamos ao ensino fundamental, etapa obrigatória, assim fixada para que a ninguém seja dado o direito de se excluir de conhecimentos considerados indispensáveis para o aproveitamento de outros direitos.

\section{Qualidade e Avaliação Externa: tensões e potencialidades}

As avaliações externas como mecanismo de aferição da qualidade dos sistemas, apesar de se constituírem num dos traços do conjunto das reformas educacionais implementadas desde a década de 1980, foram, também, marcadas por vicissitudes, por conta de diferenças de objetivos e papéis no contexto dessas reformas, bem como por resistências a esse tipo de avaliação (Bonamino; Franco, 1999).

Apesar de se apresentar como um movimento produtor de contradição tanto do ponto de vista de iniciativa política como também de aceitação dessa política, o que temos assistido é uma profusão de implementação de sistemas de avaliação, em todos os níveis da federação. Assim, se a década de 1980 foi de fortalecimento do SAEB para que sua primeira aferição fosse realizada na década seguinte, os anos 1990 foram marcados pela expansão de políticas de avaliação externa 
pelos estados do país e nos anos 2000 foi a vez dos municípios aderirem ao movimento nacional e criarem seus próprios sistemas de avaliação (Sousa; Pimenta; Machado, 2012, p. 18-19).

Assim, as avaliações externas vêm, cada vez mais, se aproximando do interior das escolas, do cotidiano educativo. Machado (2013, p. 52) pondera que,

[...] ao passo que as avaliações externas vão ampliando sua capilaridade pelo sistema educacional, chegando às escolas pelas ações dos diversos entes federados, elas vão amplificando também sua proximidade com o cotidiano das escolas e com os seus profissionais, impactando mais ainda na gestão escolar. É significativo destacar que a proximidade das avaliações com as gestões é uma tendência crescente que podemos observar na trajetória da implantação de políticas avaliativas no país, o que evidencia a perspectiva de aproximação cada vez maior.

Por ter um caráter que, necessariamente, articula aspectos técnicos com sua dimensão política, conforme os aportes de Sousa e Oliveira (2010, p. 796), para os quais a “[...] discussão da avaliação de sistemas abrange um amplo leque de questões de natureza técnica e, para além delas, implicações de ordem política, pois está intimamente vinculada às políticas públicas de educação”, as avaliações imprimem compreensões e reações das mais diversas naturezas no contexto avaliado. Assim, a efetivação da aproximação das avaliações externas com o cotidiano escolar se realiza com um grau de tensão, embora aponte também para algumas potencialidades. Cabe ainda sublinhar que são poucos e recentes os estudos e pesquisas que se debruçam sobre essa dimensão da avaliação, do seu impacto nas escolas, de acordo com Machado (2012).

Oliveira (2011, p. 137), apoiando-se em Nevo (1998), destaca que as avaliações externas parecem ter sido desenhadas muito mais para produzir informações para os gestores de redes educacionais “[...] do que para ajudar os professores a analisarem os resultados buscando rever seus métodos de ensino e práticas de avaliação". De acordo com a autora, “[...] as comunicações de resultados das avaliações com foco na escola devem promover uma articulação com o trabalho pedagógico escolar de maneira a aprimorá-lo”.

Como alerta Gimeno Sacristán (1998, p. 320), a existência de avaliações externas pode comprometer, pela ênfase na crença de seus resultados como portadores da "última palavra", os necessários debates críticos sobre a situação educacional e seus procedimentos, além de submeter os professores a uma pressão externa, "subtraindo-lhes a autonomia profissional” e impedindo-os, contraditoriamente, de desenvolver trabalho mais profícuo com seus alunos. Frente a isto, coloca-se como imperativo a busca de um processo mais amplo de avaliação de escolas e redes que, para além da utilização de provas padronizadas, tenha presente o caráter político da educação escolar e vislumbre encetar 
Qualidade das Escolas

uma avaliação institucional (Belloni, 1999; Brandalise, 2010). Reconhecer este caráter implica reconhecer profissionais e usuários das escolas como sujeitos que precisam ser considerados como tais nos processos avaliativos, pois, sem omitir-lhes as responsabilidades, são eles que, nos ambientes escolares, materializam a tarefa educativa.

Ainda no sentido de problematizações em face do processo de incorporação das avaliações externas às políticas educacionais, é relevante o conjunto de ponderações efetuadas por Stobart (2010), que ressalva efeitos perversos e indesejáveis dessa modalidade de avaliação por se afastar das pretensões de uma avaliação para a aprendizagem, ou seja, que se constituiria num ponto para a inclusão com sucesso de todos os alunos concernidos à escolarização obrigatória.

A pesquisa nacional Bons resultados no Índice de Desenvolvimento da Educação Básica: estudo exploratório de fatores explicativos ${ }^{1}$, desenvolvida de 2009 a 2011, abarcou 20 municípios do estado de São Paulo, com pelo menos 1.000 matrículas no ensino fundamental da rede municipal, que apresentaram os maiores resultados no índice para o ano de 2007, ou as maiores variações entre 2005 e 2007, para os anos iniciais do ensino fundamental. A análise teve como foco os fatores da política educacional que possivelmente explicariam os resultados obtidos por tais municípios. Foram entrevistados gestores de diversos segmentos hierárquicos e obtivemos depoimentos sobre o potencial das avaliações externas contribuírem com processos de melhoria da qualidade das escolas ${ }^{2}$. Os secretários dos municípios, por exemplo, quando entrevistados, afirmaram utilizar os dados das avaliações externas no acompanhamento do desempenho das escolas, na análise de suas necessidades educacionais e na aprendizagem dos alunos.

Para compreender quais fatores das políticas educacionais se destacavam quando associados aos resultados do IDEB, foram agregados os resultados do IDEB de 2009 com o objetivo de verificar quais municípios da amostra da pesquisa nacional apresentaram crescimento em todas as três aferições do IDEB (2005, 2007 e 2009) e, também, apresentaram crescimento nos indicadores de aprovação e proficiência em língua portuguesa e matemática. Dos 20 municípios que compuseram a amostra no estado de São Paulo, encontramos seis que nas três aferições apresentaram crescimento no IDEB e, também, em todos os indicadores que compõem o IDEB: aprovação e proficiência de língua portuguesa e matemática. Dentre os seis municípios, três possuem sistema próprio de avaliação externa (Cajuru, Catanduva e Porto Ferreira) e um já teve seu sistema municipal de avaliação (Itanhaém). Na Tabela 1 temos a série histórica dos resultados desses quatro municípios, que possuem ou já possuíram sistema próprio de avaliação nas aferições do IDEB de 2005, 2007 e 2009. 
Tabela 1 - IDEB. Redes municipais. Cajuru, Catanduva, Porto Ferreira e Itanhaém (2005-2009).

\begin{tabular}{|c|c|c|c|}
\hline Abrangência geográfica & $\mathbf{2 0 0 5}$ & $\mathbf{2 0 0 7}$ & $\mathbf{2 0 0 9}$ \\
\hline Cajuru & 5,2 & 7,0 & 8,2 \\
\hline Catanduva & 3,9 & 5,1 & 6,1 \\
\hline Porto Ferreira & 3,9 & 5,0 & 5,3 \\
\hline Itanhaém & 4,3 & 4,9 & 5,4 \\
\hline
\end{tabular}

Fonte: MEC/INEP.

O cotejamento desses dados evidencia o constante - e expressivo - crescimento para o conjunto das redes municipais e, também, o fato de que são redes que partem de resultados relativamente baixos, quando comparados com os resultados do estado de São Paulo, que foram 4,5 em 2005, 4,8 em 2007 e 5,3 em 2009.

Assim, no âmbito da referida pesquisa nacional, observamos uma associação entre a existência de sistema próprio de avaliação externa e crescimento nos indicadores do IDEB, o que sugere uma tendência nas políticas educacionais no que tange à implementação de avaliações externas com vistas ao incremento da qualidade. Contudo, esse delineamento deve ser objeto de novas investigações que permitam aquilatar, com maior profundidade e precisão, essa tendência.

Estudo de Machado (2012, p. 79) aborda a importância que as avaliações externas têm para as políticas educacionais, com suas reverberações na gestão educacional e na elevação da aprendizagem, e conclui que,

\begin{abstract}
As avaliações externas, especialmente a Prova Brasil [...] fornecem dados que, se apropriados de forma consistente, podem revigorar os contornos da escola pública que realiza a sua função social na sociedade democrática de garantir o ensino-aprendizagem para todos os seus alunos. Porém, a avaliação da escola e a reflexão sobre sua realidade não podem se esgotar nelas, que podem ser tomadas como o ponto de partida para a trajetória da escola rumo à sua avaliação institucional, que não pode prescindir de uma autoavaliação.
\end{abstract}

As quatro redes municipais possuem dimensões, em matrículas e número de escolas, bastante diversificadas, conforme a Tabela 2 .

Tabela 2 - Ensino fundamental. Séries iniciais. Matrículas e Escolas. Redes municipais. Cajuru, Catanduva, Porto Ferreira e Itanhaém (2009).

\begin{tabular}{|c|c|c|}
\hline Abrangência geográfica & Matrículas & Escolas \\
\hline Cajuru & 1.829 & 7 \\
\hline Catanduva & 5.117 & 14 \\
\hline Porto Ferreira & 3.074 & 9 \\
\hline Itanhaém & 7.683 & 30 \\
\hline
\end{tabular}

Fonte: MEC/INEP 
No escopo deste trabalho, constatamos que a dimensão das redes, tanto em termos de matrículas quanto em termos do número de escolas, não foi um obstáculo para o crescimento da qualidade da educação, compreendida nas condições consideradas no cálculo do IDEB. Guardadas as proporções, isso permite-nos evocar as contribuições de Beisiegel (1981), pois, por exemplo, a rede municipal de Itanhaém, mesmo sendo quatro vezes maior que a de Cajuru, também teve acréscimo constante no período estudado.

As taxas de aprovação dos municípios em questão apresentaram ampliação nos anos iniciais do ensino fundamental nas três aferições da Prova Brasil, conforme números da Tabela 3 demonstrados a seguir.

Tabela 3 - Taxa de aprovação. Ensino fundamental. Anos iniciais. Redes municipais. Cajuru, Catanduva, Porto Ferreira e Itanhaém (2005-2009).

\begin{tabular}{|c|c|c|c|}
\hline Redes municipais & $\mathbf{2 0 0 5}$ & $\mathbf{2 0 0 7}$ & $\mathbf{2 0 0 9}$ \\
\hline Cajuru & 91,7 & 94,0 & 97,0 \\
\hline Catanduva & 85,6 & 92,5 & 93,8 \\
\hline Porto Ferreira & 89,2 & 91,0 & 91,4 \\
\hline Itanhaém & 91,8 & 92,4 & 94,1 \\
\hline
\end{tabular}

Fonte: MEC/INEP.

Mediante os dados da Tabela 4, na qual constam as proficiências médias dos alunos em matemática e língua portuguesa, dos anos iniciais do ensino fundamental das redes nas três aferições da Prova Brasil, também configura-se o constante crescimento relativo às redes em questão.

Tabela 4 - Prova Brasil. Proficiência em Matemática (M) e Língua Portuguesa (LP). Cajuru, Catanduva, Porto Ferreira e Itanhaém (2005-2009).

\begin{tabular}{|c|c|c|c|c|c|c|}
\hline \multirow{2}{*}{ Municípios } & \multicolumn{2}{|c|}{ Prova Brasil 2005 } & \multicolumn{2}{c|}{ Prova Brasil 2007 } & \multicolumn{2}{c|}{ Prova Brasil 2009 } \\
\cline { 2 - 7 } & M & LP & M & LP & M & LP \\
\hline Cajuru & 218,60 & 194,40 & 269,80 & 236,33 & 306,54 & 276,05 \\
\hline Catanduva & 183,80 & 167,60 & 211,47 & 191,21 & 242,96 & 212,88 \\
\hline Porto Ferreira & 175,80 & 169,60 & 212,53 & 189,87 & 223,73 & 195,68 \\
\hline Itanhaém & 185,80 & 173,60 & 206,24 & 186,45 & 223,40 & 194,86 \\
\hline
\end{tabular}

Fonte: MEC/INEP.

Salientamos alguns elementos que permitem estabelecer os contornos dos sistemas municipais de avaliação implantados pelas redes municipais, nos quais são identificadas algumas características comuns.

Desde 2005, ano de implantação do sistema próprio de avaliação, em Cajuru as avaliações são diagnósticas e organizadas pela Secretaria 
de Educação e pelas escolas, com assessoria do Núcleo de Apoio à Municipalização do Ensino (NAME).

Em Catanduva, o Sistema de Avaliação do Rendimento Escolar de Catanduva (SAREMCA), instituído pela Resolução no 5 de 13 de Novembro de 2008, abrange todas as etapas da educação básica atendidas pelo município: educação infantil, ensino fundamental regular e educação de jovens e adultos, consistindo de uma prova que é aplicada uma vez ao ano que serve como base comparativa para os resultados da Prova Brasil. Ao mesmo tempo, foi criado o Índice de Desenvolvimento da Educação do Município de Catanduva (IDEMCA), apresentado como indicador da qualidade de ensino, como um instrumento de diagnóstico e controle do desempenho dos alunos, estabelecendo metas para cada escola, favorecendo o seu acompanhamento pela equipe escolar e comunidade. Em cada unidade escolar existe uma Comissão de Acompanhamento da Avaliação composta por professores, especialistas da educação e pais de alunos voluntários.

Em Porto Ferreira, com a assessoria do Instituto Ayrton Senna, foi criado o sistema próprio de avaliação externa, em 2008. Nessa rede, os dados de outras avaliações externas (Prova Brasil, Provinha Brasil, SARESP) são, também, utilizados pelo Departamento de Educação do município para detectar os problemas de aprendizagem enfrentados nas escolas, planejar ações e analisar o desempenho dos professores.

Em Itanhaém foi realizada avaliação externa pelo município somente em 2005, com assessoria externa, quando teve início a gestão da atual secretária, para efetuar um diagnóstico da rede municipal. Entretanto, a cada três meses, a Secretaria de Educação avalia a aprendizagem nas escolas, via os portfólios dos alunos organizados pelas unidades de ensino.

Nos municípios de Cajuru e Catanduva as avaliações externas municipais têm como objeto tanto o desempenho de professores quanto de alunos, já em Porto Ferreira e Itanhaém somente os alunos. Cajuru avalia os professores com foco na assiduidade, jornada, formação continuada e participação no fórum de educação, mas isso não é revertido em bônus. Em Catanduva, ao contrário, os professores recebem incentivo financeiro por assiduidade e, desde 2009, também por desempenho da escola segundo o desempenho dos alunos no SAREMCA.

Em Cajuru e Catanduva as avaliações são de caráter diagnóstico, inclusive as do NAME, e seus resultados são utilizados para repensar as ações pedagógicas. Em Porto Ferreira os dados são utilizados pelo Departamento de Educação para detectar os problemas de aprendizagem enfrentados nas escolas da rede municipal de educação. De acordo com a equipe técnica do Departamento, a partir dos dados coletados é possível ver como está a educação no município e planejar ações. Os diretores são responsáveis por discutir com os professores possíveis ações que podem ser desenvolvidas na escola para melhorar os resultados das 
Qualidade das Escolas

avaliações. Em Itanhaém o acompanhamento da política educacional do município é realizado por meio das metas de aprendizagem e do uso do sistema apostilado nas escolas. Para tanto, a cada três meses, a Secretaria de Educação avalia a aprendizagem nas escolas através dos portfólios dos alunos organizados pelas unidades de ensino. Além disso, existem visitas constantes da equipe da Secretaria (supervisores e assessores pedagógicos) às escolas.

Em geral, esses sistemas municipais de ensino assumem os resultados de suas avaliações como equivalentes à qualidade do ensino desenvolvido em suas escolas, como se as proficiências, embora relevantes, pudessem representar toda a riqueza do processo educacional e espelhar todo o trabalho docente desenvolvidos nas escolas.

Além disso, estudo de Sousa, Pimenta e Machado (2012, p. 35-36), que debate a relação das avaliações com as gestões municipais, salienta ponderações que, embora mereçam maior investigação, devem ser levadas em consideração quando debatemos as tensões das avaliações externas na sua relação com o cotidiano escolar. Em relação ao fato de as avaliações externas, em geral, priorizarem algumas disciplinas as autoras ressaltam que "[...] há indícios de uma redução curricular que se consolida, pouco a pouco, com a valorização dos conteúdos de Língua Portuguesa e Matemática".

Este mesmo estudo aponta que, para os gestores municipais, a necessidade de ter diagnóstico do desenvolvimento dos alunos é a justificativa para a criação dos sistemas próprios de avaliação, embora, destacam as autoras, "[...] os dados disponibilizados pela Prova Brasil permitem às escolas e ao sistema de ensino, informações que possibilitam diagnósticos de várias ordens, subsidiando políticas educacionais" (Sousa; Pimenta; Machado 2012, p. 34).

A semelhança do delineamento dos sistemas de avaliação empreendidos pelos municípios investigados com aqueles implementados pelos governos federal e estadual sugere uma possível adesão a um modismo vigente nas gestões públicas, que se justifica com a crença equivocada de que a avaliação é, por si só, indutora de qualidade. Em outras palavras, acredita-se que, quanto mais se avalia, mais qualidade tem a educação. Ao que parece, o governo federal, ao fomentar a regulação da educação básica via "medida-avaliação-informação" logrou seu objetivo de "[...] induzir unidades federadas a práticas de regulação avaliativa e suscitar o interesse da população pelo tema da avaliação educacional" fazendo surgir assim o "Estado-avaliador no Brasil" (Freitas, 2007, p. 190-191).

Os contornos dos sistemas próprios de avaliação externa dos municípios aqui abordados, mesmo que sucintamente, oferecem pistas e indicações para investigações ulteriores, especialmente no que tange ao uso dos resultados e seu potencial de incidir positivamente na qualidade. Alternativamente, pode-se vislumbrar o cotejamento dos resultados das avaliações internas com aqueles das avaliações externas, 
inclusive como expediente para se avaliar as próprias avaliações desencadeadas no interior das escolas. Neste último caso, considerando-se que as avaliações externas, da maneira como são conduzidas no Brasil, não tem permitido que elas também sejam avaliadas, o que, aliás, ressalta parte de sua fragilidade de legitimidade política junto a vários segmentos educacionais.

A concepção de avaliação como um processo amplo de subsídio para tomada de decisões no âmbito dos sistemas de ensino é algo recente no Brasil, e deve ser entendido como um processo que vise contemplar competências e habilidades, o próprio currículo, os hábitos de estudo dos alunos, as estratégias de ensino dos professores, o tipo de gestão dos diretores e os recursos a eles oferecidos para melhor realizar o seu trabalho.

Nesse sentido, a avaliação é um processo e uma condição necessários para que se possam estabelecer e acompanhar metas qualitativas e quantitativas e verificar se estas últimas são atingidas. Com esse foco, a avaliação é capaz de fomentar nas escolas e nas redes uma interpelação sistemática sobre a qualidade de suas práticas e dos seus resultados, articular os contributos da avaliação externa com a cultura e os dispositivos de autoavaliação das escolas e reforçar a capacidade destas para desenvolverem a sua autonomia, regulando o funcionamento do sistema educativo. "A avaliação em qualquer de suas acepções deve ter um forte caráter formativo, levando em consideração que seu objetivo é compreender melhor a realidade e, dessa forma, atuar sobre ela, dentro dos limites impostos pelos instrumentos utilizados" (Horta Neto, 2010, p. 89).

O movimento de valorização da avaliação externa vem configurando-a hoje como um dos principais elementos das políticas educacionais no sentido da melhoria da qualidade na educação e tal particularidade, também, se apresenta firmada nos municípios da amostra.

Observamos nos municípios pesquisados um movimento que articula a avaliação externa própria com iniciativas para repensar e planejar as ações pedagógicas, tanto as que dizem respeito à política educacional quanto às referidas a cada escola, na perspectiva da elaboração e uso de resultados das avaliações mais participativas. Outro movimento detectado se expressa no uso de resultados para o pagamento de bônus por mérito para professores, o que compromete seu envolvimento com a avaliação em tela e os responsabiliza, quase exclusivamente, pelos resultados dos alunos.

No primeiro caso, as avaliações são postas como subsídios para se repensar as políticas e práticas pedagógicas com foco nas funções diagnóstica e formativa da avaliação educacional. Tais funções destacam o fato de que testes ou provas não se configuram como avaliação, mas, sim, são instrumentos e procedimentos que favorecem a avaliação.

Se a qualidade na educação é um fenômeno complexo que possui determinações intraescolares, tais como currículo, formação docente, 
Qualidade das Escolas

gestão escolar, avaliação da aprendizagem, condições de trabalho, infraestrutura das escolas etc., e extraescolares, tais como condições de vida da população, capital econômico, cultural e social das famílias dos alunos, entorno social da escola, distribuição de renda, violência, entre outros, o aumento do desempenho dos alunos nos exames é parte importante desse fenômeno, ainda que este não se esgote naquele, pois a medição da aprendizagem permite o aprofundamento do diagnóstico da situação da educação brasileira e o delineamento de iniciativas de políticas educacionais nesse terreno.

Assim, devemos enxergar as informações provindas da avaliação como indícios do processo de ensino e de aprendizagem, evidenciando trajetórias dos alunos, das escolas e das próprias redes, possibilitando apoiar decisões e reconfigurações pedagógicas.

No segundo movimento, acabamos por enxergar políticas de responsabilização que podem, ao contrário do que se deseja, acabar favorecendo a lógica da meritocracia e culpabilização, dificultando a organização dos agentes escolares a partir de princípios democráticos. Frente a processos de responsabilização que se valem da distribuição de bônus, um conjunto de respostas de cunho utilitarista pode surgir em algumas escolas ou redes de ensino, para melhor se localizarem em rankings decorrentes da divulgação dos resultados obtidos, como destacou Freitas (2011).

Esta proposta de responsabilização parte do princípio de que é possível utilizar os resultados dos alunos para aferir o desempenho do professor e de outros profissionais da educação, apesar de inúmeros estudos salientarem que os alunos estão sujeitos a muitos outros fatores que extrapolam o alcance da escola e seus professores.

Nos municípios estudados, observou-se a valorização das políticas de acompanhamento e avaliação da aprendizagem. Os sujeitos dessa avaliação, quando considerada como processo e condição para se estabelecer e acompanhar metas qualitativas e quantitativas, acabam por julgar necessário desenvolver uma avaliação em âmbito municipal que dê conta de mensurar as proficiências dos alunos e, a partir daí, fornecer subsídios para o delineamento de políticas educacionais municipais. Pois, como destaca Sousa (1997b, p. 131), é "[...] fundamental o desvelamento dos princípios que norteiam as práticas avaliativas, procedendo à sua análise não apenas em uma dimensão técnica, mas, também, em uma dimensão política e ideológica".

Então, a escolha por tornar o município responsável pela elaboração e aplicação de uma avaliação externa em larga escala como política de rede se apresenta aos gestores municipais como uma possibilidade de maior controle dos processos, o que parece não ser possível quando esta é de responsabilidade do governo federal ou estadual. Secretários de educação e/ou núcleos de avaliação existentes nos municípios passam a acompanhar de perto os processos de elaboração dos testes, aplicação e avaliação, e utilização destes dados para implementação de

430 Educação \& Realidade, Porto Alegre, v. 39, n. 2, p. 413-436, abr./jun. 2014 Disponível em: <http://www.ufrgs.br/edu_realidade> 
novas políticas de rede. Isso se justifica, de acordo com Afonso (2009), pelas funções simbólicas de controle social e legitimação política dadas pela avaliação que, apesar de menos referidas, tem um maior interesse analítico quando se pensa na avaliação para além dos limites do espaço pedagógico.

Outro ponto de fundamental importância tanto para a política local quanto para a própria aceitação e validação da avaliação externa própria é a participação de outros segmentos envolvidos no processo educativo nos desenvolvimentos dos elementos acima descritos. Profissionais lotados nas Secretarias de Educação, gestores escolares, professores, pais e alunos são chamados a participar de todo o processo de avaliação, se apropriando do espaço e da discussão. Se apoiando no desenvolvimento do processo coletivo de ação-reflexão-ação, inserindo atores que tradicionalmente ocupam o papel de objeto e não sujeito da avaliação externa e, com isso, reconhecendo a importância deles como interlocutores da gestão educacional, sustentando transformações até mesmo nas relações de poder e subordinação existentes. Dessa maneira, diminui-se fortemente a resistência a aceitação dessas políticas de acompanhamento educacional e torna todos os agentes corresponsáveis pela sua implementação.

Muitas das políticas municipais de avaliação procuram envolver os processos microssociológicos que, de acordo com Brandalise (2010), ocorrem no âmbito da sala de aula e referem-se à avaliação da aprendizagem, de responsabilidade do docente. Consideram, ainda, que avaliações como SARESP e Prova ou Provinha Brasil não dão conta de apresentar resultados específicos por escola, disciplina, turma e aluno, pois se encontram no nível macrossociológico da avaliação, que é aquele desenvolvido em âmbito nacional, por organismos externos à escola, objetivando a verificação da qualidade do ensino e da educação no país. Dessa maneira, as iniciativas de avaliação própria, intencionam articular esses dois níveis, garantindo, adicionalmente, um tratamento das particularidades da realidade local.

Cabe, contudo, ressalvar a análise apresentada por Sousa, Pimenta e Machado (2012, p. 34) sobre,

[...] a urgência da avaliação e análise pedagógica sobre o excesso de provas oficiais às quais os alunos são submetidos regularmente. Ainda, merece atenção e aprofundamentos analíticos futuros a questão da fragilidade técnica das avaliações empreendidas pelos municípios, pois a forma de fazer a avaliação pode falsear dados e induzir as redes municipais não a acertos, mas, sim, a equívocos.

Com efeito, pode-se sublinhar, de um lado, a importância das avaliações externas próprias como ponto de apoio para o acompanhamento do desenvolvimento de alunos e escola e a tomada de decisões, inclusive com a participação dos diversos segmentos que compõem as redes. De outro, não estão afastados os efeitos deletérios da adoção de

Educação \& Realidade, Porto Alegre, v. 39, n. 2, p. 413-436, abr./jun. 2014.431 Disponível em: <http://www.ufrgs.br/edu_realidade> 
Qualidade das Escolas

políticas de avaliação, notadamente quando ou transferem responsabilidades de gestores para professores ou se assentam em condições precárias de realização que, por sua vez, comprometem a própria qualidade de seus resultados.

Finalmente, nos marcos da tendência da centralidade que a avaliação tem tido no papel de servir como diretriz para o desencadeamento das políticas educacionais governamentais, a nosso ver não se trata de desprezar as avaliações e tão pouco seus resultados, cabe, antes, analisar os processos avaliativos objetivando compreender seus limites e ressaltar suas potencialidades, principalmente aquelas que podem contribuir com a construção de alternativas pedagógicas para as políticas e as escolas cumprirem suas funções a sociedade democrática de oferecer educação pública de qualidade para todos seus alunos e alunas.

Recebido em 03 de agosto de 2013 Aprovado em 14 de março de 2014

\section{Notas}

1 Pesquisa coordenada pelos Professores Romualdo Portela de Oliveira, Sandra Zákia Sousa e Ocimar Munhoz Alavarse da Universidade de São Paulo, desenvolvida em rede com a Universidade Federal da Grande Dourados e a Universidade Estadual do Ceará, sob a coordenação, respectivamente, das Professoras Dirce Nei de Freitas e Sofia Lerche Vieira.

2 As informações estão baseadas na coleta de dados nestes municípios que contou, segundo o relatório da pesquisa nacional, com a participação de doutorandos, mestrandos e graduandos da FEUSP: Vanda Mendes Ribeiro, Cláudia Oliveira Pimenta, Aline Nicodemo, Érica Sayuri Nakahara Nukui, Kátia Cantamessa Godo, Laura Gonçalves, Luana Vadilleti Pereira, Maiara Mian Terra, Malena Carvalho, Maria Helena Bravo, Dalva Franco.

\section{Referências}

ADAMS, Don; ACEDO, Clementina; POPA, Simona. In: Search of Quality Education. In: ADAMS, Don; ACEDO, Clementina; POPA, Simona (Org.). Quality and Qualities: tensions in education reforms. Rotterdam: Sense; Paris: Unesco: International Bureau of Education, 2012. (Comparative and International Education: a Diversity of Voices, v. 16). P. 1-22.

ADAMS, Don; ACEDO, Clementina; POPA, Simona. Quality Education: challenges and policy choices. In: ADAMS, Don; ACEDO, Clementina; POPA, Simona (Org.). Quality and Qualities: tensions in education reforms. Rotterdam: Sense; Paris: Unesco: International Bureau of Education, 2012. (Comparative and International Education: a Diversity of Voices, v. 16). P. 197-208.

AFONSO, Almerindo Janela. Avaliação Educacional: regulação e emancipação. São Paulo: Cortez, 2009.

ALAVARSE, Ocimar; BRAVO, Maria Helena; MACHADO, Cristiane. Avaliação como Diretriz das Políticas Educacionais dos Governos Federal, Estaduais e Municipais: o caso brasileiro. In: III CONGRESSO IBERO-AMERICANO DE POLÍTICA E ADMINISTRAÇÃO DA EDUCAÇÃO. Zaragoza, 2012. 
ALVES, Fátima. Qualidade na Educação Fundamental Pública nas Capitais Brasileiras: tendências, contextos e desafios. Belo Horizonte: Argumentum, 2009.

AZEVEDO, Janete. A Temática da Qualidade e a Política Educacional no Brasil. Educação \& Sociedade, Campinas, n. 49, especial, p. 449-467, dez. 1994.

BARRETO, Elba Siqueira de Sá; PINTO, Regina Pahim. Avaliação na Educação Básica: 1990-1998. Cadernos de Pesquisa, v. 114, p. 49-88, nov. 2001.

BEISIEGEL, Celso de Rui. Relações entre a Quantidade e a Qualidade no Ensino Comum. Ande, São Paulo, n. 1, p. 49-56, 1981.

BELLONI, Isaura. Avaliação Institucional: um instrumento de democratização da educação. Linhas Críticas, v. 5, n. 9, p. 31-58, jul./dez. 1999.

BOLÍVAR, Antonio. Melhorar os Processos e os Resultados Educativos: o que nos ensina a investigação. Tradução de Mónica Franco. Nova Gaia: Fundação Manuel Leão, 2012. (Desenvolvimento Profissional de Professores, 16).

BONAMINO, Alicia Catalano; FRANCO, Creso. Avaliação e Política Educacional: o processo de institucionalização do SAEB. Cadernos de Pesquisa, São Paulo, n. 108, p. 101-132, nov. 1999.

BONAMINO, Alicia Catalano. Tempos de Avaliação Educacional: o SAEB, seus agentes, referências e tendências. Rio de Janeiro: Quartet, 2002

BONAMINO, Alicia Catalano; SOUSA, Sandra Zákia Lian. Três Gerações de Avaliação da Educação Básica no Brasil: interfaces com o currículo da/na escola. Educação e Pesquisa, São Paulo, v. 38, n. 2, p. 373-388, abr./jun. 2012.

BRANDALISE, Mary Angela Teixeira. Avaliação Institucional da Escola: conceitos, contextos e práticas. Olhar de Professor, Ponta Grossa, v. 13, n. 2, p. 315-330, 2010.

BRASIL. Presidência da República. Casa Civil. Subchefia para Assuntos Jurídicos. Decreto No 6.094, de 24 de abril de 2007. Dispõe sobre a implementação do Plano de Metas Compromisso Todos pela Educação, pela União Federal, em regime de colaboração com Municípios, Distrito Federal e Estados, e a participação das famílias e da comunidade, mediante programas e ações de assistência técnica e financeira, visando à mobilização social pela melhoria da qualidade da educação básica. Brasília, 2007.

CASASSUS, Juan. A Escola e a Desigualdade. Brasília: Líber Livro Editora, 2007

CASTRO, Maria Helena Guimarães. O Desafio da Qualidade. In: ITUASSU, Arthur; ALMEIDA, Rodrigo de (Org.). O Brasil tem Jeito?: v. 2: educação, saúde, justiça e segurança. Rio de Janeiro: Jorge Zahar, 2007. P. 35-72.

COELHO, Maria Inês de Matos. Vinte Anos de Avaliação da Educação Básica no Brasil: aprendizagens e desafios. Ensaio: Avaliação e Políticas Públicas em Educação, Rio de Janeiro, v. 16, n. 59, p. 229-258, abr./jun. 2008.

CORREIA, José Alberto. La "evaluocracia”: el papel de la evaluación en la legitimación y reconstrucción institucional de la educación. Entrevista y traducción de José Luis San Fabián Maroto. Avances en Supervisión Educativa, n. 13, p. 1-9, oct. 2010.

DOURADO, Luiz Fernando (Org.). A Qualidade da Educação: conceitos e definições. Brasília: MEC/Inep, 2007.

ENGUITA, Mariano Fernandéz. O Discurso da Qualidade e Qualidade do Discurso. GENTILI, Pablo; SILVA, Tomaz Tadeu (Org.). Neoliberalismo, Qualidade Total e Educação: visões críticas. Petrópolis, RJ: Vozes, 1994. P. 93-110.

Educação \& Realidade, Porto Alegre, v. 39, n. 2, p. 413-436, abr./jun. 2014. 
FERNANDES, Reynaldo. Índice de Desenvolvimento da Educação Básica (IDEB). Brasília: Instituto Nacional de Estudos e Pesquisas Educacionais Anísio Teixeira (INEP), 2007. 26 p. (Série Documental. Textos para Discussão, 26).

FERNANDES, Reynaldo; GREMAUD, Amaury. Qualidade da Educação: avaliação, indicadores e metas. In: VELOSO, Fernando et al. (Org.). Educação Básica no Brasil: construindo o país do futuro. Rio de Janeiro: Elsevier, 2009. P. 213-238.

FRANCO, Creso; ALVES, Fátima; BONAMINO, Alicia. Qualidade do Ensino Fundamental: políticas, suas possibilidades, seus limites. Educação \& Sociedade, Campinas, v. 28, n. 100, especial, p. 989-1014, out. 2007.

FREITAS, Dirce Nei Teixeira de. A Avaliação da Educação Básica no Brasil: dimensão normativa, pedagógica e educativa. Campinas: Autores Associados, 2007. (Educação Contemporânea).

FREITAS, Luiz Carlos. Responsabilização, Meritocracia e Privatização: conseguiremos escapar do neotecnicismo? In: III SEMINÁRIO DE EDUCAÇÃO BRASILEIRA DO CEDES. Campinas. Fevereiro de 2011.

GENTILI, Pablo. O Discurso da "Qualidade" como Nova Retórica Conservadora no Campo Educacional. In: GENTILI, Pablo; SILVA, Tomaz Tadeu (Org.). Neoliberalismo, Qualidade Total e Educação: visões críticas. Petrópolis, RJ: Vozes, 1994. P. 111-177.

GIMENO SACRISTÁN, José. A Avaliação no Ensino. In: GIMENO SACRISTÁN, José; PÉREZ GÓMEZ, Angel. Compreender e Transformar o Ensino. 4. ed. Tradução de Ernani F. da Fonseca Rosa. Porto Alegre: Artmed, 1998. P. 295-351.

GUSMÃO, Joana Buarque. Significados da Noção de Qualidade da Educação na Arena Educacional Brasileira. Revista Brasileira de Estudos Pedagógicos, Brasília, v. 94, n. 236, p. 100-124, jan./abr. 2013.

HADDAD, Fernando. O Plano de Desenvolvimento da Educação: razões, princípios e programas. Brasília: Instituto Nacional de Estudos e Pesquisas Educacionais Anísio Teixeira, 2008. 23 p. (Série Documental. Textos para Discussão, 30).

HORTA NETO, João Luiz. Avaliação Externa de Escolas e Sistemas: questões presentes no debate sobre o tema. Revista Brasileira de Estudos Pedagógicos, Brasília, v. 91, n. 227, p. 84-104, jan./abr. 2010.

MACHADO, Cristiane. Impactos da Avaliação Externa nas Políticas de Gestão Educativa. Revista Iberoamericana sobre Calidad, Eficacia y Cambio en Educación, Madrid, v. 11, n. 1, p. 40-55, jan./mar. 2013.

MACHADO, Cristiane. Avaliação Externa e Gestão Escolar: reflexões sobre o uso dos resultados. Revista @mbienteeducação, São Paulo, v. 5, n. 1, p. 70-82, jan./jun. 2012.

MORAES, Carmen Sylvia Vidigal; ALAVARSE, Ocimar Munhoz. Ensino Médio: possibilidades de avaliação. Educação \& Sociedade, Campinas, v. 32, n. 116, p. 807-838, jul./dez. 2011.

NEVO, David. Avaliação por Diálogos: uma contribuição possível para o aprimoramento escolar. In: TIANA, Alejandro (Org.). In: SEMINÁRIO INTERNACIONAL DE AVALIAÇÃO EDUCACIONAL, 1997. Anais... Tradução de John Stephen Morris. Brasília: Instituto Nacional de Estudos e Pesquisas Educacionais (Inep): 1998. P. 89-97.

OLIVEIRA, Ana Paula de Matos. A Prova Brasil como Política de Regulação da Rede Pública do Distrito Federal. 276 f. Dissertação (Mestrado) - Programa de Pós-Graduação em Educação, Universidade de Brasília, Brasília, 2011. 
OLIVEIRA, Romualdo Portela; ARAUJO, Gilda Cardoso. Qualidade do Ensino: uma nova dimensão da luta pelo direito à educação. Revista Brasileira de Educação, São Paulo, n. 28, p. 5-23, jan./abr. 2005.

OLIVEIRA, Romualdo Portela. Da Universalização do Ensino Fundamental ao Desafio da Qualidade: uma análise histórica. Educação \& Sociedade, Campinas, v. 28, n. 100, p. 661- 690, out. 2007.

ORGANIZAÇÃO PARA COOPERAÇÃO E DESENVOLVIMENTO ECONÔMICO (OCDE). As Escolas e a Qualidade. Rio Tinto: Asa, 1992. (Biblioteca Básica de Educação e Ensino).

PILATI, Orlando. Sistema Nacional de Avaliação da Educação Básica - SAEB. Ensaio: Avaliação e Políticas Públicas em Educação, Rio de Janeiro, v. 2, n. 1, p. 11-30, 1994.

RISOPATRON, Veronica Edwards. El Concepto de Calidad de la Educación. Chile: Unesco/Orealc, 1991.

SAVIANI, Demerval. O Plano de Desenvolvimento da Educação: análise do projeto do MEC. Educação \& Sociedade, Campinas, v. 28, n. 100-especial, p. 12311255, out. 2007.

SILVA, Tomaz Tadeu. O Projeto Educacional da Nova Direita e a Retórica da Qualidade Total. In: SILVA, Tomaz Tadeu; GENTILI, Pablo. Escola S. A.: quem ganha e quem perde no mercado educacional do neoliberalismo. Brasília: CNTE, 1996. P. 167-188.

SOARES, José Francisco. Qualidade da Educação: qualidade de escolas. In: VIANA, Fabiana Silva et al. A Qualidade da Escola Pública no Brasil. Belo Horizonte: Mazza, 2012. P. 75-96.

SOUSA, Sandra Zákia Lian. Avaliação do Rendimento Escolar como Instrumento de Gestão Educacional. In: OLIVEIRA, Dalila. Gestão Democrática da Educação: desafios contemporâneos. Petrópolis: Vozes, 1997a. P. 264-283.

SOUSA, Sandra Zákia Lian. Avaliação Escolar e Democratização: o direito de errar. In: AQUINO, Julio Groppa (Org.). Erro e Fracasso na Escola: alternativas teóricas e práticas. São Paulo: Summus, 1997b. P. 125-138.

SOUSA, Sandra Zákia Lian; ARCAS, Paulo Henrique. Implicações da Avaliação em Larga Escala no Currículo: revelações de escolas estaduais de São Paulo. Educação: Teoria e Prática, Rio Claro, v. 20, n. 35, p. 181-199, jul./dez. 2010.

SOUSA, Sandra Zákia Lian; LOPES, Valéria V. Avaliação nas Políticas Educacionais Atuais Reitera Desigualdades. Revista Adusp, São Paulo, n. 46, p. 53-59, jan. 2010.

SOUSA, Sandra Zákia Lian; OLIVEIRA, Romualdo Portela. Sistemas Estaduais de Avaliação: uso dos resultados, implicações e tendências. Cadernos de Pesquisa, São Paulo, v. 40, n. 141, p. 793-822, set./dez. 2010.

SOUSA, Sandra Zákia Lian; PIMENTA, Claudia; MACHADO, Cristiane. Avaliação e Gestão Municipal da Educação. Estudos em Avaliação Educacional, São Paulo, v. 23, n. 53, p. 14-36, set./dez. 2012.

STOBART, Gordon. Tiempos de Pruebas: los usos y abusos de la evaluación. Traducción de Pablo Manzano Bernández. Madrid: Morata: Ministerio de Educación, 2010.

VIANNA, Heraldo Marelim. Fundamentos de um Programa de Avaliação Educacional. Brasília: Liber Livro, 2005.

WEBER, Silke. Relações entre Esferas Governamentais na Educação e PDE: o que muda? Cadernos de Pesquisa, São Paulo, v. 38, n. 134, p. 305-318, maio/ago. 2008. 
Cristiane Machado é doutora em Educação pela Universidade de São Paulo (2003). Atualmente é docente do Mestrado em Educação da Universidade do Vale do Sapucaí - Univás, em Pouso Alegre/MG, onde coordena o Gepaq (Grupo de Estudos e Pesquisas em Formação Docente, Avaliação e Qualidade). Desenvolve pesquisas relacionadas aos temas: Avaliação Educacional, Política Educacional, Gestão Educacional e Escolar e Formação Docente. Participa do Gepave (Grupo de Estudos e Pesquisas em Avaliação Educacional) na Faculdade de Educação da USP.

E-mail: cristiane13machado@yahoo.com.br

Ocimar Munhoz Alavarse é licenciado em Pedagogia pela Universidade Federal de São Carlos-SP (1984), Mestre (2002) e Doutor (2007) em Educação pela Universidade de São Paulo. Atualmente é professor da Faculdade de Educação da Universidade de São Paulo, onde coordena o Grupo de Estudos e Pesquisas em Avaliação Educacional (Gepave). Atua principalmente nos seguintes temas: ciclos, progressão continuada, avaliação educacional e gestão educacional.

E-mail: ocimar@usp.br 